\title{
Early marriage, poor reproductive health status of mother and child well-being in India
}

\author{
Ravi Prakash, ${ }^{1}$ Abhishek Singh, ${ }^{2}$ Praveen Kumar Pathak, ${ }^{3}$ Sulabha Parasuraman ${ }^{4}$
}

'Manager, Department of Monitoring and Evaluation, Karnataka Health Promotion Trust, Bangalore, India ${ }^{2}$ Assistant Professor, Department of Public Health and Mortality Studies, International Institute for Population Sciences (IIPS), Mumbai, India

${ }^{3}$ Assistant Professor, Department of Geography, Shivaji University, Kolhapur, India

4Professor and Head, Department of Population Policies and Programmes, International Institute for Population Sciences (IIPS), Mumbai, India

\section{Correspondence to}

Ravi Prakash, PhD, Department of Monitoring and Evaluation, Karnataka Health Promotion Trust, IT Park, 5th Floor, \#1-4, Rajajinagar Industrial Area, Rajajinagar, Bangalore 560044, India; ravistats@gmail.com

Received 13 June 2009 Accepted 5 January 2011 Published Online First 31 May 2011

\begin{abstract}
Background and methodology Early marriage, women's poor reproductive health and child well-being are important areas of concern, especially in developing countries like India. Data from the third wave of National Family Health Survey (NFHS, 2005-2006) was used to examine the effects of early marriage on the reproductive health status of women and on the well-being of their children.

Bivariate analyses, multiple linear regression and logistic regression were used for analyses. Results The results show that early age at marriage had detrimental effects on the reproductive health status of women. Women married at an early age were exposed to frequent childbearing, unplanned motherhood and abortions, which negatively affected their nutritional status. Children born to mothers with poor reproductive health had lower chances of survival and a higher likelihood of anthropometric failure (i.e. stunting, wasting and underweight).

Discussion and conclusions Programmes should focus on delaying entry of adolescents into wedlock and motherhood through information, education and communication. More emphasis needs to be put on meeting the reproductive needs of poor adolescent mothers, and improving the nutritional status of their children, to break the vicious circle of poor reproductive health and poverty.
\end{abstract}

\section{Introduction}

Population activists at the 1994 International Conference on Population and Development (ICPD) shifted their interest from family planning as a means of slowing population growth to overall protection of the reproductive health and rights of women, ${ }^{1}$ whereas poverty reduction was one of the important concerns for the Millennium Development Goals (MDGs) and for developmental agencies

\section{Key message points}

Early age at marriage had a detrimental effect on the reproductive health of women.

Children born to women with poor reproductive health had poor nutritional status and lower chances of survival.

- To break the cycle of poor reproductive health and poverty we need to provide programmes to delay entry into motherhood and to meet the needs of poor adolescent mothers.

such as the World Bank and developing nations like India.

After the ICPD conference, it was expected that the investment for population programmes would be enhanced to support this new approach, but this has not happened. Doubts raised included:

- Will investments in reproductive health reduce poverty, help countries to achieve MDGs and reduce the burden of disease?

- How strong is the evidence that poor sexual and reproductive health outcomes inhibit poverty reduction compared to other problems, including general health [AIDS, malaria, tuberculosis (TB), and so on]? ${ }^{2}$

Studies have noted the poor health status of women as a predominant consequence of early childbearing. Early marriage (i.e. before the legal age of marriage of 18 years for females in India) usually leads to early debut into sexual activities. ${ }^{34}$

The analysis of Demographic Health Survey data from 40 countries shows that $20-50 \%$ of women enter marriage under the age of 18 years while $40-70 \%$ do so by their 20th birthday. ${ }^{5}$ In many developing countries, between one-half and three-quarters of all first births to married women occur within 2 years of first union. ${ }^{67}$ That is, early marriage typically leads to childbearing at younger ages. The third round of the Indian National Family Health Survey (NFHS-3) also shows that of all women aged 15-49 years, 60\% 
married before reaching the legal minimum marriage age of 18 years and $73 \%$ of these women had their first child by 18 years of age. ${ }^{8}$ Studies from other developing countries indicated that each additional year of delay for marriage is associated with an estimated reduction of 0.27 pregnancies. ${ }^{9}$

Adolescent pregnancies account for $10 \%$ of total births around the globe, $15 \%$ of the global burden of disease due to poor maternal health conditions and $13 \%$ of maternal deaths. ${ }^{3}$ A study in 1998 showed that the maternal mortality for young women aged 15-19 years was higher, compared to women aged 20-34 years, in countries like Ethiopia, Indonesia, Bangladesh, Nigeria, Brazil and the USA. ${ }^{10} 11$

Other studies confirm that early pregnancy confers higher risk on mothers and their infants. Young mothers are more prone to deliver before the 36th week of pregnancy, have prolonged/complicated deliveries and repeated pregnancies followed by abortion. Moreover, adolescent mothers are estimated to account for 14\% of all unsafe abortions. ${ }^{12}{ }^{13}$ Studies from Nepal, ${ }^{14}{ }^{15}$ India, ${ }^{16}$ ${ }^{17}$ Bangladesh, ${ }^{18}$ Sri Lanka ${ }^{19}$ and Ethiopia ${ }^{20}$ provide evidence that pregnancy in adolescence results in poorer obstetric outcomes compared to pregnancy during adulthood. However, studies from developed countries are not so definite. While some studies have reported poorer outcomes among younger married women, ${ }^{21} 22$ others have shown no difference or even better outcomes among late adolescents compared to older women, ${ }^{23} 24$ which may be due to the availability and quality of prenatal care and the better nutritional status of younger married girls in developed countries. A literature review on health consequences of adolescent childbearing in developing countries by Kurz ${ }^{25}$ concluded that primiparity, continued growth during pregnancy, quality of obstetric antenatal care and poor socioeconomic status are major risk factors associated with poor outcomes of adolescent pregnancy. This was supported by the World Health Organization (WHO) analyses of 25 studies, which found an association between pre-term birth and the mother's nutritional status. The WHO analysis concluded that women with pre-pregnancy weight and height of less than $45 \mathrm{~kg}$ and $145 \mathrm{~cm}$, respectively, were more likely to bear low birthweight or premature infants, stillbirths and neonatal deaths including insufficient growth among the children due to an inadequate supply of the women's milk. ${ }^{26}$

A study conducted by Rahman and others in urban hospitals in Bangladesh indicated that the child's nutritional status was associated with the body mass index (BMI) of the mother. ${ }^{27}$ Similarly, Christian et al. ${ }^{28}$ established a relationship between maternal well-being and the nutritional status of the child.

Although a few attempts have been made to show the effect of early marriage and health status of women on child survival and child health, ${ }^{3} 6916$ none of the studies have attempted to capture the composite effect of the reproductive health status of the mother on child health. We examined the effect of age at marriage on reproductive health status of women and the impact of the mother's reproductive health status on child well-being.

\section{Data and methodology}

The data used in the study come from the third round of NFHS carried out in India during 2005-2006. ${ }^{8}$ [NB. The NFHS is a large-scale, multi-round survey conducted in a representative sample of households throughout India. The third NFHS (NFHS-3), conducted in 20052006 , is the outcome of collaborative efforts of many organisations including the International Institute for Population Sciences, Macro International, US Agency for International Development, Department for International Development, the Bill and Melinda Gates Foundation, United Nation Children's Fund, United Nation Population Fund and Ministry of Health and Family Welfare. The survey also includes information on several emerging issues such as perinatal mortality, male involvement in maternal health care, adolescent health care, higher-risk sexual behaviour, family-life education, safe injections and knowledge about TB.] The survey covers a representative sample of 109041 households, 124385 women aged 15-49 years and 74369 men aged 15-54 years. The NFHS-3 sample covers $99 \%$ of India's population living in all 29 states that were captured in two phases from November 2005 to August 2006. The principal objective of NFHS-3 was to provide state and national level estimates on fertility, mortality, family planning, HIV-related knowledge and important aspects of nutrition, health and health care. The survey provides state-level estimates of demographic and health parameters as well as data on various socioeconomic and programme dimensions.

The data used in this study come from 39026 currently married women in the reproductive age group (15-49 years) who gave birth to at least one child in the 5 -year period preceding the survey. The data were analysed to examine the effect of early marriage on the reproductive health status of the women and the association between the reproductive health status of the women and their experience of any child loss.

A total of 50673 births were recorded in the 5 years preceding the survey. The information on these births was analysed to examine the effect of a mother's reproductive health status on the nutritional status of her children. Appropriate sampling weights have been used in the analyses to adjust for the non-response and multistage stratified sampling design of the survey. The women have been categorised into three groups on the basis of age at first marriage (i.e. those women who were married by 14 years of age, 15-17 years and greater than 17 years of age).

\section{Analyses}

The analysis was done in two parts. In the first part we looked at whether early age at marriage of women 
leads to poor reproductive health, whereas in the second part the association between the reproductive health status of mothers and the well-being of their children was analysed.

The reproductive health status of women was measured using a weighted composite index, the Reproductive Health Index (RHI). The RHI uses seven reproductive health indicators: mother's age at first birth, pregnancy complications, wantedness of last child, abortion, stillbirth, mother's BMI and anaemia. Pregnancy complications, wantedness of last child, experience of any abortion, and stillbirths were converted into dichotomous variables, while the variables on mother's age at first birth, BMI and anaemia had three or more categories.

Separate weights were assigned to each variable. The weights to the categories of the dichotomous variables were assigned in such a manner that women experiencing any negative reproductive health outcome had a penalty of 0 , whereas women experiencing any positive reproductive health outcome had a reward of 1 (Appendix 1). For example, a woman experiencing any pregnancy complication gets a weight of 0 , while those who do not experience any pregnancy complication get a weight of 1 . The same procedure of weighting is followed in the case of the other three dichotomous variables. However, in the case of polychotomous variables, a slightly different scheme of weighting has been employed. For example, women who first gave birth when aged 14 years or under were assigned a weight of 0 , those who first gave birth when aged 15-17 years were assigned a weight of 1 , and others who first gave birth when aged over 18 years were given a weight of 2 .

Similarly, underweight $\left(<18.5 \mathrm{~kg} / \mathrm{m}^{2}\right)$ and overweight $\left(\geq 25.0 \mathrm{~kg} / \mathrm{m}^{2}\right)$ women were assigned 0 whereas normal weight $\left(18.5-24.9 \mathrm{~kg} / \mathrm{m}^{2}\right)$ women were given a score of 1 . Likewise, a woman with severe anaemia was assigned 0 , mild and moderately anaemic women were assigned 1 and non-anaemic women were assigned a weight of 2 . Thus women without any poor reproductive health outcomes have the highest score and vice versa. The RHI ranges between a theoretical minimum of 0 to a maximum of 9 .

The RHI was classified into three categories: poor (0-5), average (6-7) and high (8-9). The categorisation of the index was done in such a way that the lowest $25 \%$ sample women were classified into poor RHI, the next 50\% into average RHI and top 25\% into high RHI. RHI was used in the analyses to understand the reproductive health burden of early marriage and the relationship of reproductive health to child well-being. Cronbach's $\alpha$ was used to check the reliability of the index.

Experience of child loss by women is a dichotomous variable (coded as 1 if the women experienced any child loss and 0 otherwise). Four separate measures of anthropometric failure, namely $z$-scores of height-forage (-2 SD), weight-for-height (-2 SD), weight-forage $(-2 \mathrm{SD})$ and any anthropometric failure were used to assess the nutritional status of children. We used the composite index of anthropometric failure (CIAF) proposed by Svedberg ${ }^{29}$ and Nandy et al. ${ }^{30}$ to capture undernutrition among children in its totality.

The independent variables used in the analysis were: the age of the respondent in years (15-19, 20-24, $25-29, \geq 30$ years), place of residence (rural, urban), educational status (no education, primary, secondary, higher), exposure to mass media (no exposure, partial exposure, full exposure), age at first sexual encounter ( $\leq 14,15-19, \geq 20$ years), marital duration $(\leq 9,10-14$, $15-19,20-24, \geq 25$ years), husband's educational status (no education, primary, secondary, higher), wealth quintile (poorest, poorer, middle, richer, richest) and region (North, Central, East, Northeast, West and South; for definition see Table 2 footnote). Exposure to mass media (radio, television and newspaper) was categorised into three categories (no exposure, partial exposure, full exposure). Partial exposure refers to one source or two sources, while full exposure includes those women who were exposed to all three types of mass media. The wealth quintile is an index of the economic status of households. This index was constructed using household asset data and housing characteristics. Each household is assigned a weight generated through principal component analysis (Filmer and Pritchett). ${ }^{31}$ The sample is divided into quintiles (i.e. five groups with an equal number of individuals in each). ${ }^{8}$ The wealth quintile is given in the NFHS-3 dataset. Regional classification of states is also made in the same line as given in NFHS-3. Since in the Indian scenario, state level socioeconomic and cultural conditions affect the overall health status of women in general and reproductive health in particular, we analysed the effect of age at marriage on RHI after adjusting for the effect of the region in which the particular women lives. In the second part of the analysis, the RHI (poor, average, high) was also used as an independent variable together with the other variables taken as predictors in the first part of the analysis.

Bivariate analysis is used to understand the differentials in age at marriage by selected socioeconomic, demographic and reproductive health status characteristics. The Chi-square $\left(\chi^{2}\right)$ test has been used to test association of age at marriage with selected socioeconomic, demographic and reproductive health status characteristics.

We used multiple linear regression models to test our first hypothesis with RHI (continuous) as the dependent variable. In the second part of the analysis, five outcome variables, namely experience of any child loss and four measures of anthropometric failure among children (stunting, wasting, underweight and any anthropometric failure among surviving 
children) have been used as dependent variables. To test our second hypothesis we use five binary logistic regression models. Wald tests were performed to test the statistical significance of the predictor variables in the logistic regressions..$^{32} 33$ The 95\% confidence interval (CI) for the odds ratio (OR) is also presented to give an idea about the precision of the estimates. The analysis was carried out using STATA $10^{\mathrm{TM}}$ Release 10.0 (Stata Corporation, College Station, TX, USA).

\section{Results}

\section{Age at first marriage and reproductive health}

Table 1 presents the three categories in accordance with the age at first marriage by selected socioeconomic and demographic characteristics. About $40 \%$ of the currently married women were aged 15-24 years. Most of these women lived in rural areas (73\%), practised Hinduism (79\%), and more than a quarter of them $(30 \%)$ belonged to socially disadvantaged groups (scheduled caste/tribe). The majority lived in poor households (46\%) and had no or a very low level of education ( $47 \%$ illiterate and $14 \%$ educated only up to primary level). Nearly $20 \%$ of the sampled women had their first sexual debut before the age of 14 years, and $64 \%$ women had a marital duration of up to 9 years. The husbands of these women also had low levels of education. About $28 \%$ of husbands had no education and $60 \%$ were educated only to primary level. More than $53 \%$ of sampled women came from the Central and East region, about 26\% from the North and West region and the remaining 21\% from the South and Northeast region of India, roughly representative of the country's population distribution as a whole.

Among women who got married up to 14 years of age, $50 \%$ were in the peak of their reproductive period (15-24 years) compared to 29\% among women who got married after the age of 18 years. The majority of the sampled women who got married at an early age were of the Hindu religion (80\%), lived in rural areas $(85 \%)$, belonged to socially disadvantaged groups $(38 \%)$, were economically poor $(68 \%)$ and were illiterate $(71 \%)$. The majority $(62 \%)$ of such women came from the Central and Eastern regions of India. Among women who married after the age of 18 years, $77 \%$ followed the Hindu religion, about $62 \%$ resided in rural areas, a smaller proportion were from relatively unprivileged social groups (only $24 \%$ ) and economically poor households (19\%), and only $29 \%$ were illiterate. The majority (61\%) of these women belonged to the Southern, Western, Northern and North-eastern regions of India. A large proportion of women married at an early age had limited exposure to sources of mass media (no exposure $=$ $46 \%$, full exposure $=5 \%$ ) compared to women married at or after the legal age of marriage (no exposure $=19 \%$, full exposure $=24 \%$ ). Interestingly, $97 \%$ of early married women had their sexual debut on or before their 14th birthday. Conversely, the majority of the women who had married at the age of 15-17 years experienced their sexual debut at an average age of 18 years or older. The educational level of the husbands of early married women was also lower than those women who married after the legal age of marriage, as $42 \%$ of husbands of early married women were illiterate compared to only $17 \%$ of husbands of women who married after the age of 17 years. The findings suggest that women who marry early mostly come from poor socioeconomic backgrounds and belong to demographically backward regions compared to women who marry later.

Table 2 presents selected reproductive health indicators by age at marriage. Age at first birth was significantly associated with age at first marriage. A majority of women had their first birth after attaining the age of 19 years (a mean age at first birth of 19.4 years) and only $10 \%$ of women gave birth below the age of 15 years $(p<0.01)$. On average, the women had given birth to three children. More than half had pregnancy complications, $18 \%$ underwent an abortion and $2 \%$ had stillbirths. Some $22 \%$ of women reported their last birth as being unwanted or mistimed. The nutritional status measured by indicators such as BMI and anaemia indicated that $40 \%$ of the women were very thin and $20 \%$ were moderate to severely anaemic $(p<0.01)$. Overall, $22 \%$ of women had poor reproductive health status, while others had average or good reproductive health status. The result of the $\chi^{2}$ test shows a statistically significant relationship between the RHI and age at first marriage of women at the $1 \%$ level of significance.

The findings show that $21 \%$ of women married by the age of 14 years or below had initiated childbearing before their 15th birthday. An additional 23\% started childbearing at age 15 years. Only $14 \%$ of these women had their first birth after age 18 years. This compares with $96 \%$ of first births after the age of 18 years among women who married when they were 18 years or older. The mean age at first birth was 16 years among those women who married before age 15 years compared to 22 years among those who married after age 17 years. The women who married early had, on an average, four children. This compares with two children among those who married later. In addition, those women who marry early were more likely than those who marry later to report pregnancy complications (46\% vs $44 \%)$ and unwanted or mistimed births ( $24 \%$ vs $20 \%$ ). Again, women married below age 15 years were far more likely than women married after age 17 years to be underweight (46\% vs 33\%) and to suffer from iron-deficiency anaemia (63\% vs $56 \%$ ).

Forty-one per cent of women married before age 15 years were in the poor reproductive health status category. In comparison, only $11 \%$ of women married after age 17 years fell into this category. Ten per cent of women married by age 14 years or below vs $31 \%$ 
Table 1 Percentage distribution of currently married women by age at first marriage according to selected characteristics of women, husband's education and region, India, 2005-2006

\begin{tabular}{|c|c|c|c|c|}
\hline \multirow[b]{2}{*}{ Characteristics } & \multicolumn{3}{|c|}{ Age at first marriage (years) } & \multirow[b]{2}{*}{ All womer } \\
\hline & $\leq 14$ & $15-17$ & $\geq 18$ & \\
\hline \multicolumn{5}{|l|}{ Current age (years) } \\
\hline $15-19$ & 17.3 & 10.0 & 0.6 & 7.6 \\
\hline $20-24$ & 32.2 & 39.6 & 28.4 & 33.6 \\
\hline $25-29$ & 26.6 & 28.1 & 39.5 & 32.5 \\
\hline$\geq 30$ & 23.9 & 22.3 & 31.5 & 26.4 \\
\hline \multicolumn{5}{|l|}{ Residence } \\
\hline Rural & 85.4 & 79.1 & 61.6 & 73.1 \\
\hline Urban & 14.6 & 20.9 & 38.4 & 26.9 \\
\hline \multicolumn{5}{|l|}{ Religion } \\
\hline Hindu & 80.4 & 80.1 & 77.4 & 79.0 \\
\hline Muslim & 17.5 & 17.1 & 15.1 & 16.3 \\
\hline Other & 2.1 & 2.9 & 7.5 & 4.6 \\
\hline \multicolumn{5}{|l|}{ Caste } \\
\hline Scheduled caste/tribe & 38.2 & 32.6 & 24.3 & 30.3 \\
\hline Other backward class & 44.0 & 42.9 & 38.8 & 41.4 \\
\hline Other castes & 17.8 & 24.5 & 36.9 & 28.3 \\
\hline \multicolumn{5}{|l|}{ Wealth index } \\
\hline Poorest & 37.8 & 27.7 & 13.9 & 23.9 \\
\hline Poorer & 29.1 & 25.2 & 14.8 & 21.7 \\
\hline Middle & 19.2 & 21.7 & 17.8 & 19.6 \\
\hline Richer & 10.4 & 17.0 & 23.5 & 18.4 \\
\hline Richest & 3.5 & 8.5 & 30.1 & 16.4 \\
\hline \multicolumn{5}{|l|}{ Educational status } \\
\hline No education & 70.6 & 54.3 & 29.5 & 47.2 \\
\hline Primary & 14.6 & 16.2 & 11.6 & 14.0 \\
\hline Secondary & 14.6 & 28.7 & 45.2 & 32.8 \\
\hline Higher & 0.1 & 0.8 & 13.7 & 6.0 \\
\hline \multicolumn{5}{|l|}{ Exposure to mass media } \\
\hline No exposure & 46.3 & 35.2 & 19.1 & 30.7 \\
\hline Partial exposure & 49.2 & 54.7 & 56.6 & 54.4 \\
\hline Full exposure & 4.5 & 10.1 & 24.3 & 14.8 \\
\hline \multicolumn{5}{|c|}{ Age at first sexual encounter (years) } \\
\hline$\leq 14$ & 96.8 & 0.5 & 0.1 & 18.8 \\
\hline $15-19$ & 3.0 & 99.4 & 49.4 & 60.4 \\
\hline$\geq 20$ & 0.2 & 0.1 & 50.5 & 20.8 \\
\hline \multicolumn{5}{|l|}{ Marital duration (years) } \\
\hline$\leq 9$ & 42.5 & 60.9 & 75.9 & 63.6 \\
\hline $10-14$ & 28.8 & 22.0 & 15.8 & 20.8 \\
\hline $15-19$ & 16.3 & 11.1 & 5.6 & 9.8 \\
\hline $20-24$ & 8.3 & 4.3 & 2.1 & 4.2 \\
\hline$\geq 25$ & 4.1 & 1.7 & 0.5 & 1.6 \\
\hline \multicolumn{5}{|c|}{ Husband's educational status } \\
\hline No education & 42.0 & 31.1 & 17.3 & 27.5 \\
\hline Primary & 18.4 & 16.2 & 11.7 & 14.8 \\
\hline Secondary & 35.2 & 45.6 & 50.9 & 45.8 \\
\hline Higher & 3.4 & 5.9 & 19.7 & 11.1 \\
\hline \multicolumn{5}{|l|}{ Region* } \\
\hline North & 11.5 & 11.6 & 14.8 & 12.9 \\
\hline Central & 30.0 & 32.3 & 23.2 & 28.1 \\
\hline East & 31.9 & 28.2 & 19.3 & 25.3 \\
\hline Northeast & 3.3 & 3.2 & 5.1 & 4.0 \\
\hline West & 8.7 & 11.9 & 15.9 & 12.9 \\
\hline South & 14.6 & 12.8 & 21.8 & 16.8 \\
\hline Total $^{\dagger}$ & 100.0 & 100.0 & 100.0 & 100.0 \\
\hline Sample & 7472 & 15533 & 16021 & 39026 \\
\hline
\end{tabular}


of women marrying after age 17 years belonged to the higher reproductive health status category.

These findings clearly suggest that women who married early not only start childbearing early, but are also more likely to report pregnancy complications, unwanted or mistimed pregnancies, are more likely to be underweight and are more likely to suffer from any form of iron-deficiency anaemia.

The results of the multiple linear regression analysis are presented in Table 3. The regression result indicates that age at marriage has a significant and positive effect on the reproductive health status of women, that is, increase in age at marriage leads to an increase in RHI. After adjusting for the effect of several characteristics, women who marry late were more likely than women who marry early to have better reproductive health [adjusted $ß$ ( $\geq 18$ years) 1.032, 95\% CI 0.98-1.07]. This result was statistically significant at the $1 \%$ level of significance. The Wald test clearly shows that age at marriage is an important predictor of the reproductive

Table 2 Percentage distribution of currently married women by age at first marriage according to selected reproductive health characteristics, mean age at first birth, mean children ever born and Reproductive Health Index (RHI), India, 2005-2006

\begin{tabular}{|c|c|c|c|c|}
\hline \multirow[b]{2}{*}{ Characteristics } & \multicolumn{3}{|c|}{ Age at first marriage (years) } & \multirow[b]{2}{*}{ All women } \\
\hline & $\leq 14$ & $15-17$ & $\geq 18$ & \\
\hline \multicolumn{5}{|l|}{ Age at first birth (years)* } \\
\hline$\leq 14$ & 20.8 & 0.5 & 0.1 & 4.2 \\
\hline 15 & 23.2 & 3.5 & 0.0 & 5.9 \\
\hline 16 & 19.2 & 12.0 & 0.1 & 8.5 \\
\hline 17 & 14.2 & 22.8 & 0.3 & 11.9 \\
\hline 18 & 8.5 & 25.4 & 3.2 & 13.0 \\
\hline$\geq 19$ & 14.1 & 35.9 & 96.2 & 56.5 \\
\hline Mean age at first birth (years) (SD) & $16.3(2.5)$ & $18.2(2.1)$ & $22.1(3.0)$ & $19.4(3.5)$ \\
\hline Mean number of children ever born (SD) & $3.6(2.0)$ & $3.0(2.0)$ & $2.4(1.6)$ & $2.9(1.9)$ \\
\hline \multicolumn{5}{|l|}{ Pregnancy complication ${ }^{\dagger}$} \\
\hline No complication & 45.5 & 44.5 & 43.8 & 44.4 \\
\hline Any complication & 54.5 & 55.5 & 56.2 & 55.6 \\
\hline \multicolumn{5}{|l|}{ Wantedness of child* } \\
\hline Unwanted/mistimed & 24.1 & 23.2 & 20.0 & 22.1 \\
\hline Wanted & 75.9 & 76.8 & 80.0 & 77.9 \\
\hline \multicolumn{5}{|l|}{ Any abortion } \\
\hline No & 80.6 & 81.7 & 81.6 & 81.4 \\
\hline Yes & 19.4 & 18.3 & 18.4 & 18.6 \\
\hline \multicolumn{5}{|l|}{ Any stillbirth* } \\
\hline No & 97.5 & 97.8 & 98.1 & 97.9 \\
\hline Yes & 1.9 & 1.6 & 1.2 & 1.5 \\
\hline \multicolumn{5}{|l|}{ BMI of women $\left(\mathrm{kg} / \mathrm{m}^{2}\right)^{\star}$} \\
\hline Underweight/thin (<18.5) & 46.3 & 44.4 & 33.2 & 40.1 \\
\hline Normal (18.5-24.9) & 50.3 & 50.7 & 53.6 & 51.9 \\
\hline Overweight/obese ( $\geq 25.0$ ) & 3.4 & 4.9 & 13.2 & 8.0 \\
\hline \multicolumn{5}{|l|}{ Anaemia among women $(\mathrm{g} / \mathrm{dl})^{*}$} \\
\hline Severe $(<7.0)$ & 2.0 & 1.9 & 1.5 & 1.8 \\
\hline Moderate (7.0-9.9) & 19.8 & 19.2 & 15.3 & 17.7 \\
\hline Mild (10.0-11.9) & 41.4 & 41.2 & 39.2 & 40.4 \\
\hline Not anaemic $(>12.0)$ & 36.7 & 37.7 & 44.0 & 40.1 \\
\hline \multicolumn{5}{|l|}{$\mathrm{RHI}^{*}$} \\
\hline Poor & 40.8 & 23.5 & 11.5 & 21.9 \\
\hline Average & 48.7 & 56.2 & 57.5 & 55.3 \\
\hline High & 10.5 & 20.3 & 31.0 & 22.8 \\
\hline Total $^{\ddagger}$ & 100.0 & 100.0 & 100.0 & 100.0 \\
\hline Sample & 7472 & 15533 & 16021 & 39026 \\
\hline \multicolumn{5}{|c|}{$\begin{array}{l}\text { Pregnancy complication is based on information for most recent birth. BMI excludes women who were pregnant at the } \\
\text { time of the survey and women who gave birth during the } 2 \text { months preceding the survey. Prevalence of anaemia in } \\
\text { women is based on women who stayed in the household the night before the interview, excluding Nagaland. } \\
{ }^{*} \chi^{2} \text { test significant at the } 1 \% \text { significance level. } \\
{ }^{+} \chi^{2} \text { test significant at the } 5 \% \text { significance level. } \\
\text { fTotal may not equal } 100 \text { on account of missing cases. Values in parentheses represent standard deviation. } \\
\text { BMI, body mass index; RHI, Reproductive Health Index; SD, standard deviation. }\end{array}$} \\
\hline
\end{tabular}


Table 3 Result of multiple regression analysis indicating the effect of change in age at marriage on reproductive health status of women, India, 2005-2006

\begin{tabular}{ll}
\hline Predictor & $\beta$ coefficient \\
\hline Age at marriage (years) & \\
$\leq 14$ & Ref \\
$15-17$ & $0.627^{*}(0.59-0.67)$ \\
$\geq 18$ & $1.032^{*}(0.98-1.07)$
\end{tabular}

The results are adjusted for age, residence, religion, caste, wealth index, educational status, mass media exposure of mothers and region. Values in parentheses represent $95 \% \mathrm{Cl}$.

*Significant at the $1 \%$ significance level.

Ref, reference category.

health status of women $(p<0.01)$. We conclude that early age at marriage leads to poor reproductive health. Women residing in urban areas, having a high level of education, belonging to a higher wealth quintile, practising the Hindu religion, belonging to 'general castes' and having mass media exposure had better reproductive health compared to their counterparts.

\section{Effect of reproductive health status of mothers on the well-being of their children}

Figure 1 shows that mothers with poor reproductive health status experienced higher child loss than those mothers who enjoyed relatively better reproductive health. Figure 2 presents the association between the reproductive health status of mothers and the nutritional status of their children. Children belonging to mothers having poor reproductive health were more likely to suffer from stunting, wasting and being underweight compared to the children of mothers who had better reproductive health. The mean RHI score of mothers by the CIAF are presented in Figure 3. Mothers of children who were at minimum risk of anthropometric failure were more likely to have a higher mean RHI score compared to mothers of children who were at maximum risk of anthropometric failure. For example, mothers of those children who had multiple nutritional deficiencies had an average RHI score of 7.6. In comparison, the mothers of children who had no nutritional deficiency had an average RHI score of 8.3.

Table 4 shows the results of the five binary logistic regression models. The findings suggest that mothers with better reproductive health status were significantly less likely to experience child loss than mothers with poor reproductive health. The odds of experiencing child loss by mothers with better reproductive health status was lower (OR 0.593, 95\% CI 0.54-0.65) compared to mothers having poor nutritional status. In addition, children belonging to mothers who had a better reproductive health status were less likely than children of women having poor reproductive health to suffer from stunting (OR 0.807, 95\% CI 0.76-0.86),

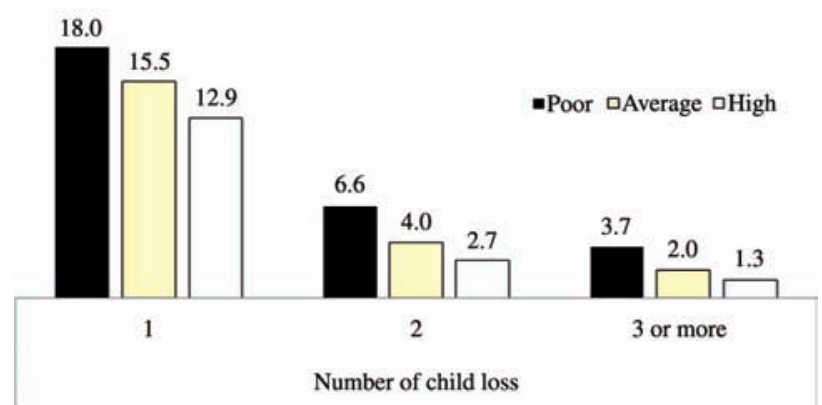

Figure 1 Percentage of currently married women (aged 15-49 years) who have given birth in the last 5 years, by child loss, according to reproductive health status, India, 2005-2006

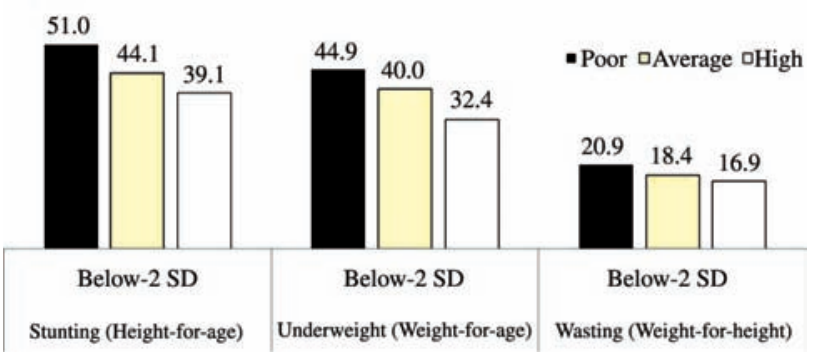

Figure 2 Percentage of anthropometric failures among children (aged $0-5$ years) by reproductive health status of the mother (aged 15-49 years), India, 2005-2006

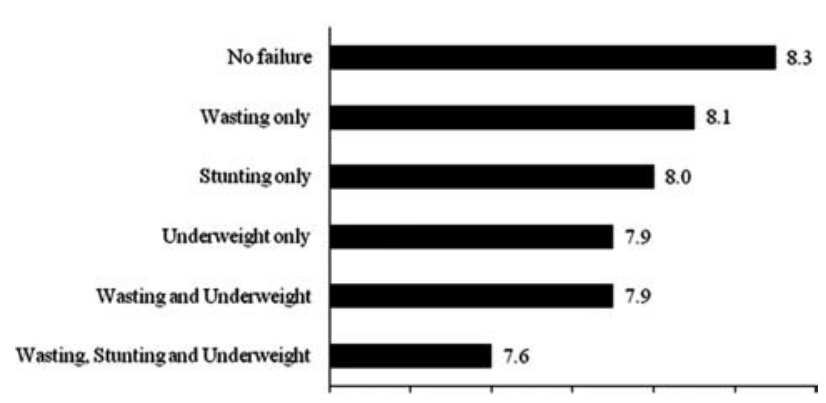

Figure 3 Mean reproductive health score of mothers (aged $15-49$ years) by subgroup of anthropometric failures among children (aged 0-5 years), India, 2005-2006

being underweight (OR 0.685, 95\% CI 0.65-0.73), wasting (OR $0.762,95 \%$ CI $0.71-0.82$ ) and any anthropometric failure (OR $0.780,95 \%$ CI $0.72-0.83$ ). All these results were statistically significant at the $1 \%$ level of significance. The results of the Wald test indicate that the reproductive health status of mothers is a significant and important predictor of the well-being of their children $(p<0.01)$. The effects of other socioeconomic and demographic covariates were found to be in the expected directions as children whose mothers had higher education, belonged to wealthier households, lived in urban areas, had higher mass media exposure and residing in the Southern, Western and Northern regions were less likely to have nutritional deficiencies and had a better chance of survival than did the 
Table 4 Adjusted odds ratio assessing association of child loss and anthropometric failures among children (aged 0-5 years) with the Reproductive Health Index of mothers, India, 2005-2006

\begin{tabular}{|c|c|c|c|c|c|}
\hline \multirow[b]{2}{*}{ RHI } & \multirow[b]{2}{*}{ Child loss } & \multicolumn{4}{|c|}{ Anthropometric failure among children (0-5 years) } \\
\hline & & Stunting & Underweight & Wasting & Any failure \\
\hline Poor & Ref & Ref & Ref & Ref & Ref \\
\hline Average & $0.719 *(0.67-0.77)$ & $0.926^{\dagger}(0.87-0.98)$ & $0.847^{*}(0.80-0.90)$ & $0.876^{*}(0.82-0.93)$ & $0.890 *(0.84-0.96)$ \\
\hline High & $0.593^{*}(0.54-0.65)$ & $0.807^{*}(0.76-0.86)$ & $0.685^{*}(0.65-0.73)$ & $0.762^{*}(0.71-0.82)$ & $0.780^{*}(0.72-0.83)$ \\
\hline \multicolumn{6}{|c|}{$\begin{array}{l}\text { Values in parenthese represent } 95 \% \mathrm{Cl} \text {. } \\
\text { * } \text { Significant at the } 1 \% \text { significance level. } \\
\text { tSignificant at the } 5 \% \text { significance level. The results are adjusted for age, residence, religion, caste, wealth index, educational status, mass media exposure of } \\
\text { mothers and region. } \\
\text { Ref, reference category; RHI, Reproductive Health Index. }\end{array}$} \\
\hline
\end{tabular}

children of mothers who belonged to other categories of these variables.

\section{Discussion and conclusions}

The analyses clearly showed that women who married early were more likely to have poor reproductive health compared to women who marry later, especially those who marry after the age of 17 years. Again, women marrying early were more likely to have experienced child loss and to have poor anthropometric indicators among their children.

Since the concept and domain of reproductive health is very comprehensive, it was beyond the scope of this paper to account for all the components separately. Therefore, we devised the weighted composite index known as the RHI, incorporating seven important components of reproductive health (i.e. mother's age at first birth, pregnancy complications, wantedness of last child, experience of any abortion, stillbirths, BMI and anaemia of those women who have given birth at least once in the past 5 years). The selection of these indicators was done on the basis of existing evidence of those factors that affect the reproductive health status of women. Women were classified as having poor, average or good reproductive health.

Since the information on all the variables was not available for all births in the last 5 years, we could not analyse the information on all births and instead restricted the analysis to the women's most recent birth only, but we felt that this was unlikely to materially influence the results.

The Cronbach's $\alpha$ values for RHI were above the acceptable limits $(\alpha=0.839)$ suggesting that the items included in the scale were reliable and were consistent with each other.

Dividing the RHI categories into three or five parts and re-running the analyses made no difference to the final results, suggesting that the RHI categories were robust.

It is clearly evident from the analyses that women who married early had lower levels of schooling, poor socioeconomic status, limited exposure to mass media and lived in demographically backward regions (i.e. Central and Eastern). These factors reduce the women's autonomy and decision-making power and participation in work. This group of women had higher fertility with short birth intervals and more unplanned pregnancies, spontaneous abortions, stillbirths and abortion exacerbating the risk of pregnancy complications, reproductive health risk and maternal mortality. Negative health outcomes increase the financial burden on households and the risk of poverty. The poor reproductive health status of the mother was also negatively associated with the well-being of their children.

Mothers with poor health and nutritional status were likely to have malnourished children and their children were more likely to die during infancy and childhood. Although information on the nutritional status of women at the time of their marriage was not available, poor reproductive health increases the economic burden on the household for preventive (food and nutrition) and curative care (for illness control), thereby intensifying the vicious circle of poverty still further. Studies show that a large proportion of children (under the age of 5 years) in developing countries (estimated at more than 200 million) do not reach their developmental potential due to ill health, poverty, malnutrition and related social factors. ${ }^{34}$ These risk factors interfere with children's development and keep them in poverty as adults and perpetuate the intergenerational cycle of poverty.

Keeping the potential consequences of early marriage in mind, efforts should be made to increase the age at which women get married. In 1954, the Indian government passed a law that prohibits parents from allowing their daughters to marry before they reach the age of 18 years. Data from NFHS-3 (2005-2006) indicate that nearly $28 \%$ of women were married below the age of 15 years and approximately 58\% below the legal marriage age of 18 years. Thus a large proportion of women are marrying below the legal age of marriage, which suggests that the actual implementation of the law pertaining to legal age at marriage is still far from being at a satisfactory level in some Indian states. From a policy point of view, the law-enforcing agencies 
should try to strictly implement the law pertaining to legal age at marriage with the purpose and spirit of stopping the menace of early marriage in India.

Some of the Indian states (i.e. Andhra Pradesh, Haryana, Karnataka, Madhya Pradesh, Punjab, Rajasthan and Tamil Nadu) provide financial incentives to girls to postpone their marriage until they attain the age of 18 years or more. Other states could usefully implement similar policies. In addition, scholarships and credit for schooling and income-generating activities for participating families can also provide some support in extending the age of marriage to the legal age. For example, a programme, commonly known as Apni Beti Apna Dhan (Our Daughters Our Wealth) launched by the Haryana Government provides 3000 rupees to the family of the girl: a gift of 500 rupees within 15 days of the birth and a further investment of 2500 rupees in a small saving scheme. If the girl remains unmarried until the age of 18 years, the gift is expected to be worth about 25000 rupees. ${ }^{36}$ This scheme is available to those families that fall below the poverty line, belong to certain disadvantageous castes and are willing to limit family size to two or three children.

Other than providing incentives, provision of female education in a broader sense together with enhanced job opportunities may also attract more females into educational facilities or into income-generating activities. This may help in postponing marriage until the women concerned are older. Studies have shown a positive association between school attendance and postponement of marriage. The longer the time spent in school, the later the entry into first marital union. ${ }^{37-39}$ Also, with an increase in the level of education of girls, their aspirations regarding getting an equally or better-educated partner may rise. As a result, the search for a suitable match may be prolonged and thus delay marriage. ${ }^{40}$ If the purpose of education is the development of career opportunities, time spent in school may be compounded with further time spent in the labour market, which is likely to raise the age of marriage.

In addition, efforts should also be made to educate parents about the consequences of early marriage. Parents play a very important role in the partner selection process and marriage timing in Indian society. Providing information to parents on the consequences of early marriage, both direct (low level of education, fewer employment opportunities, greater pregnancy burden, poor maternal health) and indirect (experience of child loss, reduced nutritional status of mother and children) may assist parents in making rational decisions regarding the marriage of their daughters.

This paper highlights the need to focus on delaying the age of marriage in developing countries like India as early age at marriage not only reduces the educational opportunities and economic freedom of girls, but also increases the poor health status of women and their children and perpetuates a greater financial burden on their families. The results of this analysis highlight the necessity for policymakers to address the urgent need to improve the reproductive health status of women, and more specifically of those women who marry at younger ages.

These findings are also relevant in the context of poverty reduction as (1) early marriage restricts education attainment among women and does not provide them with opportunities to participate in economic activity, (2) early marriage and early childbearing lead to poor reproductive health of women, which in turn affect children's health and exert a dual financial burden on the household expenditure for maternal and child health care and (3) the poor health of children leads to low educational attainment and thus further restricts their participation in income-generating activities. Children born to mothers with poor reproductive health status have significantly lower chances of survival and are more prone to suffer from anthropometric failures. It is now appropriate to focus on the reproductive health needs of adolescent mothers, which could help India achieve the MDGs.

Acknowledgements An earlier version of this paper was presented at the Annual Meeting of the Indian Association for the Study of Population (IASP) held in Bangalore, India, 17-19 October 2008. The authors are grateful to comments provided by Professor T K Roy, Emeritus Professor at the International Institute for Population Sciences, Mumbai, India.

\section{Competing interests None.}

\section{Provenance and peer review Not}

commissioned; externally peer reviewed.

\section{References}

1 Green ME. Poor health, poor women: how poor reproductive health affects poverty. Focus 2008;16:111.

2 Greene ME, Merrick T. Poverty Reduction: Does Reproductive Health Matter? Health, Nutrition, and Population Discussion Paper. Washington, DC: The World Bank, 2005.

3 World Health Organization and United Nation Population Fund. Pregnant Adolescents: Delivering on Global Promises of Hope: Executive Summary. Geneva, Switzerland: WHO, 2006.

4 International Centre for Research on Women. Too Young to Wed: Education \& Action Toward Ending Child Marriage. Report of Child Marriage and Health. Washington, DC: International Centre for Research on Women, 2006.

5 Singh S, Sharma R. Early marriage among women in developing countries. Int Fam Plan Perspect 1996;22:148-157, 175.

6 Alan Guttmacher Institute. Hopes and Realities: Closing the Gap Between Women's Aspirations and Their Reproductive Experiences. New York, NY: Alan Guttmacher Institute, 1995:48-49.

7 Westoff CF, Blanc AK, Nyblacde L. Marriage and Entry into Parenthood (DHS Comparative Studies, Number10). Calverton, NY: Macro International, 1994.

8 International Institute for Population Sciences and ORC Macro. National Family Health Survey (NFHS-3), India Report: Volume I. Mumbai, India: International Institute for Population Sciences, 2007. 
9 Field E. Consequences of Early Marriage for Women in Bangladesh. 2004. http://ipc.umich.edu/edts/pdfs/FieldEM904. pdf [accessed 14 December 2010].

10 Family Care International and the Safe Motherhood InterAgency Group. The Safe Motherhood Initiative. New York, NY: FCI, 1998.

11 Centres for Disease Control and Prevention. Vital Statistics Report. Atlanta, GA: CDC, 2002.

12 World Health Organization. Adolescent Pregnancy: Unmet Needs and Undone Deeds (Unpublished Review of Literature and Programs). Geneva, Switzerland: WHO, 2003.

13 World Health Organization. Post-Abortion Family Planning: A Practical Guide for Program Managers. Geneva, Switzerland: WHO, 1997.

14 Dali SM, Pradhan N. Obstetric performance of adolescent pregnancy at TUTH. J Inst Med 1992;14:13-19.

15 Malla DS, Shrestha PL. Adolescent Pregnancy and Its Outcome (Mimeograph). Kathmandu, Nepal: Maternity Hospital, 1996.

16 Ambadkar NN, Khandait DW, Zodpey SP, et al. Teenage pregnancy outcome: a record based study. Indian J Med Sci 1999;53:14-17.

17 Verma V, Das KB. Teenage primigravidae: a comparative study. Indian J Public Health 1997;41:52-55.

18 Alam N. Teenage motherhood and infant mortality in Bangladesh: maternal age-dependent effect of parity one. J Biosoc Sci 2000;32:229-236.

19 Weerasekara DS. Adolescent pregnancies - is the outcome different? Ceylon Med J 1997;42:16-17.

20 Kumbi S, Isehak A. Obstetric outcome of teenage pregnancy in northwestern Ethiopia. East Afr Med J 1999;76:138-140.

21 Amini SB, Catalano PM, Dierker LJ, et al. Births to teenagers: trends and obstetric outcomes. Obstet Gynecol 1996;87:668674.

22 Satin AJ, Leveno KJ, Sherman ML, et al. Maternal youth and pregnancy outcomes: middle school versus high school age groups compared with women beyond the teen years. Am J Obstet Gynecol 1994;171:184-187.

23 Yoder BA, Young MK. Neonatal outcomes of teenage pregnancy in a military population. Obstet Gynecol 1997;90:500-506.

24 Mukasa FM. Comparison of pregnancy and labour in teenagers and primigravidas aged 21-25 years in Transkei. S Afr Med J 1992;81:421-423.

25 Kurz K. Health Consequences of Adolescent Childbearing in Developing Countries (ICRW Working Paper Number 4). Washington, DC: International Center for Research on Women (ICRW), 1997.

26 World Health Organization. Maternal Weight Gain and Pregnancy Outcomes (Bulletin of the World Health Organization, Supplementary Volume 73). Geneva, Switzerland: WHO, 1995.

27 Rahman M, Roy SK, Ali M, et al. Maternal nutritional status as a determinant of child health. J Trop Pediatr 1993;39:86-88.

28 Christian PS, Gujral S, Abbi RD, et al. Relationship between maternal and infant nutritional status. J Trop Pediatr 1989;35:71-76.

29 Svedberg P. Poverty and Undernutrition: Theory, Measurement and Policy. New Delhi, India: Oxford India Paperworks, 2000.

30 Nandy S, Irving M, Gordon D, et al. Poverty, child undernutrition and morbidity: new evidence from India. Bull World Health Organ 2005;83:210-216.
31 Filmer D, Pritchett LH. Estimating wealth effects without expenditure data - or tears: an application to educational enrollments in states of India. Demography 2001;38:115-132.

32 Agresti A. Categorical Data Analysis. New York, NY: John Wiley \& Sons, 1990.

33 Polit D. Data Analysis and Statistics for Nursing Research. Stamford, CT: Appleton \& Lange, 1996.

34 Engle PL, Black MM, Behrman JR, et al. Strategies to avoid the loss of developmental potential in more than 200 million children in the developing world. Lancet 2007;369:229-242.

35 Walker SP, Wachs TD, Gardner JM, et al. Child development: risk factors for adverse outcomes in developing countries. Lancet 2007;369:145-157.

36 Lloyd CB. Growing Up Global: The Changing Transitions to Adulthood in Developing Countries. Washington, DC: The National Academies Press, 2005.

37 Marini MW. The transition to adulthood: sex differences in educational attainment and age at marriage. Am Sociol Rev 1978;43:483-507.

38 Lee GR. Family Structure and Interaction: A Comparative Analysis (2nd edn). Minneapolis, MN: University of Minnesota Press, 1982.

39 Hogan DP. The effects of demographic factors, family background, and early job achievement on age at marriage. Demography 1978;15:161-175.

40 Prakash R. Inter-generational changes in mate selection and marriage age in urban Varanasi. Unpublished $\mathrm{PhD}$ thesis, International Institute for Population Sciences, Mumbai, India, 2010.

Appendix 1 Scores assigned to the different components of the Reproductive Health Index (RHI)

\begin{tabular}{ll}
\hline RHI components & Score \\
\hline Pregnancy complication & \\
No complication & 1 \\
Any complication & 0 \\
Wantedness of child & \\
Unwanted/mistimed & 0 \\
Wanted & 1 \\
Any abortion & \\
No & 1 \\
Yes & 0 \\
Any stillbirth & \\
No & 1 \\
Yes & 0 \\
Mother's age at first birth (years) & \\
$\leq 14$ & 0 \\
15-17 & 1 \\
18-45 & 2 \\
Body mass index of women $\left(\mathrm{kg} / \mathrm{m}^{2}\right)$ & \\
Underweight/hin $(<18.5)$ & 0 \\
Normal $(18.5-24.9)$ & 1 \\
Overweight/obese $(225.0)$ & 0 \\
Anaemia among women $(\mathrm{g} / \mathrm{dll})$ & \\
Severe $(<7.0)$ & 0 \\
Moderate $(7.0-9.9)$ & 1 \\
Mild $(10.0-11.9)$ & 1 \\
Not anaemic $(>12.0)$ & 2 \\
$\quad$ &
\end{tabular}

